Stephen Willott,

RCGP SDHIV Group, Clinical Lead for Drug Misuse \& Alcohol for NHS Nottingham City, Windmill Practice, Nottingham, NG2 4PJ.

Email: stephen.willottagp-c84683.nhs.uk

\section{Euan Lawson,}

RCGP Substance Misuse Unit, Greenmantle, Marthwaite, Sedbergh, Cumbria.

\section{REFERENCES}

1. Fitzpatrick M. Older addicts. Br J Gen Pract 2011; 61(589): 522.

2. Department of Health (England), the Scottish Government, Welsh Assembly Government and Northern Ireland Executive Drug misuse and dependence: UK guidelines on clinical management. London: Department of Health, 2007.

http://www.dh.gov.uk/en/Publicationsandstatistics/ Publications/PublicationsPolicyAndGuidance/DH_1 04819 laccessed ( Sep 2011).

3. Ford C, Halliday K, Lawson E, Browne E. Guidance for the use of substitute prescribing in the treatment of opioid guidance in primary care. London: Royal College of General Practitioners 2011

4. Gossop M, Marsden J, Stewart D, Treacy S. Outcomes after methadone maintenance and methadone reduction treatments: two-year follow up results from the National Treatment Outcomes Research Study. Drug Alcohol Depend 2001; 62(3): 255-264.

5. Kimber J, Copeland L, Hickman M, et al. Survival and cessation in injecting drug users: prospective observational study of outcomes and effect of opiate substitution treatment. BMJ 2010; 340 c3172.

6. Ward J, Hall W, Mattick R. Role of maintenance treatment in opioid dependence. Lancet 1999; 353(9148): 221-226.

7. Ghodse H, Corkery J, Ahmed K, Naidoo V, et al. Drug-related deaths in the UK: annual report 2010. London: St George's, University of London, 2010

\section{Ubi Scientia in the midst of the cosy cardigans of Caritas?}

Daniel Edgcumbe makes an eloquent plea for GPs to engage with the body of knowledge relating to health services, systems, and policy-making, ${ }^{1}$ As a GP engaged in research in this area I can only wholeheartedly agree with his analysis.
However, I believe there are significant problems within the world of general practice research that militate against this occurring.

First, established disciplinary boundaries render much of the work that my colleagues and I do invisible. Journals such as the $B M J$ and, on occasion, the BJGP, are often unsympathetic to research that is qualitative, emergent, and theory generating. Much of the work in this field is cross-disciplinary, and finds a home in journals such as Sociology of Health and Illness, Social Policy and Administration, and the excellent Journal of Health Services Research and Policy. However, such journals have lower impact factors than biomedical journals Itypical social science journal impact factors are less than 2, compared with a figure of 13 for the BMJ), and this means that our work is undervalued within university medical faculties. Furthermore, it has been my experience las a reviewer and as an applicant) that the scoring systems used to decide which abstracts are worthy of a presentation slot at academic conferences, such as the Society for Academic Primary Care, are biased in favour of clinical and quantitative research, making it difficult to find an audience for the work that we do.

Second, and leading on from this, even academic medics appear to be unaware of the wide ranging and excellent body of research that exists in the field of social sciences. As an illustration of this, my colleagues and I undertook a large and detailed study of practice-based commissioning; work that is clearly relevant in the current political context. This work was extensively published in journals that appear on PubMed and Medline, and a simple search for 'practice-based commissioning' on Google Scholar ${ }^{\text {Ti }}$ retrieves many of these papers and the project reports within the first few pages of results. Indeed, we lalong with colleagues from the London School of Hygiene and Tropical Medicine) are so well recognised as experts in the field of commissioning research that we were recently awarded a contract to set up a Policy Research Unit on Commissioning and the Healthcare System, funded by the Department of Health. In spite of this, when the RCGP decided to set up a Centre for Commissioning not only were we not contacted, but an email offering support went unanswered for nearly 6 months.

I straddle two worlds, being a practising GP and an active researcher in the field of social science and health policy. As such both know the literature and know the reality of life on the ground. While I am only too aware that busy GPs do not have time to wade through long papers in sociology journals, those journals with a mass GP audience such as the BJGP and the BMJ owe it to us to at least attempt to signpost and summarise the relevant research. In addition, I would encourage our academic institutions such as the RCGP and the SAPC to engage more fully with the wider world of research, acknowledging our junior place in a well-established academic field and signalling our openness to learn and engage with research paradigms beyond the randomised controlled trial.

Kath Checkland,

University of Manchester, 5th Floor, Williamson Building, Oxford Road,

Manchester, M13 9PL.

E-mail: kath.checklandamanchester.ac.uk

Conflict of interest: I am a member of the Editorial Board of the BJGP.

\section{REFERENCE}

1. Edgcumbe D. Ubi Scientia in the midst of the cosy cardigans of Caritas? Br J Gen Pract 2011; 61(586): 345

DOI: 10.3399/bjgp11X601307 